\title{
Health promotion in the general practice consultation: a minute makes a difference
}

\author{
A Wilson, P McDonald, L Hayes, J Cooney
}

\begin{abstract}
Objective-To see whether extending appointment length from seven and a half minutes or less to 10 minutes per patient would increase health promotion in general practice consultations.

Design-Controlled trial of 10 minute appointments. Consultations were compared with control surgeries in which the same doctors booked patients at their normal rate (median six minutes per patient).

Setting - 10 general practices in Nottinghamshire.

Subjects -16 general practitioners were recruited. Entry criteria were a booking rate of eight or more patients an hour, a wish for longer consultations, and plans to increase appointment length.
\end{abstract}

Main outcome measures-Duration of consultations; recording of blood pressure, weight, and cervical cytology in the medical record; recording of advice about smoking, alcohol, diet, exercise, and immunisation in the medical record; reporting of the above activities by patients.

Results-Mean consultation times were 8.25 minutes in the experimental sessions and 7.04 and $7 \cdot 16$ minutes in the control sessions. Recording of blood pressure, smoking, alcohol consumption, and advice about immunisation was significantly more frequent in the experimental sessions, and the proportion of consultations in which one or more items of health education were recorded in the medical notes increased by an average of over $6 \%$ in these sessions. Patients more often reported discussion of smoking and alcohol consumption and coverage of previous health problems in the experimental sessions. There was little change in discussion of exercise, diet, and weight or cervical cytology activity.

Conclusions - Shortage of time is a major factor in general practitioners' failure to realise their potential in health promotion. General practice should be organised so that doctors can run 10 minute appointment sessions.

Department of Genera

Practice, The Medical

School, Queen's Medical

Centre, Nottingham

NG7 2UH

A Wilson, MRCGP, lecturer

P McDonald, BSC, research assistant

L Hayes, MA, research assistant

J Cooney, MSC, research assistant

Correspondence to:

Dr A Wilson, Department of

General Practice, Clinical

Sciences Building, Leicester

Royal Infirmary, PO Box 65

Leicester LE2 7LX.

$B M \mathcal{F}$ 1992;304:227-30

\section{Introduction}

The importance of health promotion in primary care has been emphasised both internationally and nationally.$^{12}$ In general practice there is debate about how to deliver this service, with increasing emphasis on health promotion clinics and use of non-medical personnel. ${ }^{3}$ Despite these developments, consultations with the doctor are the most common encounters in primary care and frequently present opportunities to raise health promotion issues directed at either the presenting complaint or the broader needs of the individual patient. ${ }^{4}$

Health promotion has been defined as "all aspects of those activities that seek to improve the health status of individuals and the community." The main contribution of the general practitioner is to discuss lifestyle factors and apply or make arrangements for specific screening tests, such as blood pressure recording or cervical cytology. ${ }^{6}$ Empirical studies suggest that this potential of the general practice consultation is not realised..$^{7-9}$

One explanation is shortage of time in the consultation. Practices with smaller list sizes have been shown to deliver higher rates of screening, possibly because of increased availability of time. ${ }^{9}$ Many confounding factors such as the personality or interests of the doctor may, however, explain this association. To date, experimental studies controlling for the doctor have been based in single practices and have produced inconsistent results, particularly in relation to screening and health education. ${ }^{10-13}$ These may reflect differences by individual doctors or be due to the relatively small number of preventive activities sampled. Many doctors booking patients at less than 10 minute intervals express a desire for longer appointments, for reasons including greater opportunities for health promotion. ${ }^{14}$ We report a controlled trial of 10 minute appointments for 16 such doctors. The aim was to discover whether among other things such a change would increase the amount of secondary and tertiary prevention in the consultation. The study measured other outcomes, including stress in the doctors, which have been reported elsewhere. ${ }^{15}$

\section{Subjects and methods}

Criteria for participation were a current booking rate of eight or more patients an hour, a desire to change to longer consultations, and plans to increase appointment length. Participants were recruited after a survey of Nottinghamshire general practitioners conducted in 1988 , which achieved a $67 \%$ response rate. Forty eight doctors fulfilled the entry criteria, and the first 16 of these to agree to take part were included. This sample was representative of those eligible in terms of age (median 36.5 years), sex $(81 \%$ male $(n=13))$, and list size (median 2200). The sample included four doctors who booked eight patients an hour, one who booked nine, 10 who booked 10 , and one who booked 12 patients an hour. Median appointment length was therefore six minutes.

Experimental surgeries with appointments booked at 10 minute intervals were timetabled to take place once a fortnight on a designated day and time for each doctor. Although all participants planned to extend their average consultation time, they could spend as little or as much time as they wished with individual patients. Two types of control surgeries were used, as far as possible matched for time of day and day of the week. The first was drawn from the period before the trial, and the second took place during the trial phase, in the alternate weeks when an experimental session was not scheduled. The first control session was included in case of any contaminating effect of the 
longer bookings on a doctor's behaviour, and the second to control for seasonal factors and any time related events, thus increasing the chance of a similar mix of patients. Roughly 300 consultations in total were included from each doctor, with about equal numbers in each of the three types of session.

$W^{\prime}$ hen possible the duration of consultation was measured by a research assistant observing the patients' entry and exit times. In four cases the layout of the surgery made this impossible. In three of these the task was delegated to a receptionist, and in one case the doctor timed herself. Entry and exit times were noted by using stopwatches with seconds displayed and total duration rounded to the nearest minute. More accurate timing of individual consultations would not have contributed to the main question of whether with longer appointments more health promotion occurred. When more than one patient entered the consulting room at the same time estimation of consultation length was not attempted, although other results were included in the analysis. A subsample of 36 sessions was audiotaped to verify these procedures, including timing of consultations.

Each medical record was reviewed by one of three research assistants at the end of the session and entries on prescribing, examination, and health education were noted according to a protocol. Extracts from this protocol related to health promotion activities are shown in the appendix. Doctors were asked to classify each problem as "new," "new episodes of previous problem," or "other." After leaving the consulting room each patient was asked to complete a questionnaire, which included questions about health education, preventive procedures and discussion of general health and previous health problems, as well as basic sociodemographic data. The subsample of consultations audiotaped was analysed for health education activity by using the same definitions as for extraction from the medical record. Interrater reliability was measured on both extraction from the medical record and audiotape analysis. Participating doctors were not

TABLE I-Duration of consultation in experimental and control sessions

\begin{tabular}{|c|c|c|c|}
\hline & $\begin{array}{l}\text { First } \\
\text { control } \\
\text { session }\end{array}$ & $\begin{array}{l}\text { Second } \\
\text { control } \\
\text { session }\end{array}$ & $\begin{array}{l}\text { Experimental } \\
\text { session }\end{array}$ \\
\hline No of surgery sessions & 91 & 96 & 112 \\
\hline No of consultations & 1514 & 1496 & 1461 \\
\hline Mean No of patients per session & $16 \cdot 6$ & $15 \cdot 6$ & $13 \cdot 0$ \\
\hline No $(\%)$ of consultations timed & $1436(94 \cdot 8)$ & $1421(95 \cdot 0)$ & $1370(93.8)$ \\
\hline Mean duration $(\min )$ & $7 \cdot 04$ & $7 \cdot 16$ & $8 \cdot 25$ \\
\hline Median duration (min) & $6 \cdot 0$ & $6 \cdot 0$ & $7 \cdot 0^{\star}$ \\
\hline $\begin{array}{l}\text { Lower quintile of duration } \\
\text { (min) }\end{array}$ & $4 \cdot 0$ & $4 \cdot 0$ & $5 \cdot 0$ \\
\hline $\begin{array}{l}\text { Upper quintile of duration } \\
\text { (min) }\end{array}$ & $9 \cdot 0$ & $10 \cdot 0$ & $11 \cdot 0$ \\
\hline
\end{tabular}

«First control session $v$ second control session: $\mathrm{p}=\mathrm{NS}$; first control session $v$ experimental session: $p<0 \cdot 001$ (Mann-Whitney $U$ test); second control session $v$ experimental session: $p<0 \cdot 001$ (Mann-Whitney U test). able to see the patient questionnaire and were not told that a main focus of the study was health promotion.

Data on consultation length were compared by using non-parametric tests. Categorical variables were compared by $\gamma^{2}$ analysis, initially between all three groups (two control, one experimental). When significant differences were observed each group was compared with the other. The McNemar sign test was used to measure the significance of differences between audiotape, medical record, and questionnaire data. Agreement was estimated by Cohen's $\varkappa$ statistic, which was also used to measure agreement between observers. ${ }^{1617}$

\section{Results}

The study included 299 sessions and 4471 consultations. Mean consultation time was over a minute longer in the experimental sessions (table I). Comparison of the patient mix in each type of session showed no differences in the frequency of new problems, new espisodes, or other problems between the experimental and second control sessions. The proportion of "other" problems was slightly higher in the first control sessions $(21 \cdot 8 \%$ compared with $15 \cdot 1 \%$ and $19 \cdot 4 \%$ in the experimental and second control sessions respectively; $p<0.01$ for each pair). Patients in the three types of surgery did not differ in age, sex, or social class distribution except that slightly fewer 5-15 year olds were seen in the experimental sessions $(8 \cdot 3 \%, 7 \cdot 7 \%$, and $4.9 \%$ in first control, second control, and experimental sessions respectively). As consultation length changed less than appointment length, waiting times for patients decreased (medians $17 \cdot 0,15 \cdot 0$, and $5 \cdot 0$ minutes in first control, second control, and experimental sessions).

The medical record was reviewed after the patient's consultation in $96.6 \%$ of cases $(97.6 \%, 95.7 \%$, and $96.6 \%$ in first control, second control, and experimental sessions respectively). Table II shows that recording of blood pressure and advice about smoking, alcohol consumption, and immunisation were significantly more frequent in the experimental sessions, as was the proportion of consultations in which one or more items of health education were recorded. Discussion about diet, weight, exercise, and cervical cytology was recorded more frequently in the experimental sessions, but these differences were not consistently significant. The proportion of consultations in which taking a cervical smear was recorded did not differ by type of surgery. Data on breast self examination are not included as this was recorded so infrequently (total five cases). The rate of prescribing did not differ between the sessions $(57 \cdot 1 \%, 55 \cdot 7 \%$, and $56.9 \%$ of consultations in first control, second control, and experimental sessions respectively).

Data from the patient questionnaire showed the same trends towards increased health promotion in the

TABLE II -Numbers (percentages) of consultations in experimental and control sessions with health promotion activities recorded in notes

\begin{tabular}{|c|c|c|c|c|c|c|}
\hline & \multirow{2}{*}{$\begin{array}{c}\text { First } \\
\text { control session } \\
\begin{array}{c}(\mathrm{n}=1478) \\
\text { (A) }\end{array}\end{array}$} & \multirow{2}{*}{$\begin{array}{c}\text { Second } \\
\text { control session } \\
(\mathrm{n}=1432) \\
\text { (B) }\end{array}$} & \multirow{2}{*}{$\begin{array}{c}\text { Experimental } \\
(\mathrm{n}=1411) \\
\text { (C) }\end{array}$} & \multicolumn{3}{|c|}{$\mathrm{p}$ Value } \\
\hline & & & & (A) $v(\mathrm{~B})$ & (A) $v(\mathrm{C})$ & (B) $v(\mathrm{C})$ \\
\hline \multicolumn{7}{|l|}{ Procedures: } \\
\hline Recording of blood pressure & $276(18 \cdot 7)$ & $267(18 \cdot 6)$ & $336(23 \cdot 8)$ & NS & $<0 \cdot 001$ & $<0.001$ \\
\hline Recording of weight & $56(3 \cdot 8)$ & $84(5 \cdot 9)$ & $98(6 \cdot 9)$ & NS & NS & NS \\
\hline Cervical smear taken & $19(1 \cdot 3)$ & $20(1 \cdot 4)$ & $21(1 \cdot 5)$ & NS & NS & NS \\
\hline \multicolumn{7}{|l|}{ Health education: } \\
\hline Smoking & $66(4 \cdot 5)$ & $67(4 \cdot 7)$ & $104(7 \cdot 4)$ & NS & $<0.001$ & $<0.01$ \\
\hline Alcohol & $13(0 \cdot 9)$ & $20(1 \cdot 4)$ & $46(3 \cdot 3)$ & NS & $<0 \cdot 001$ & $<0.01$ \\
\hline Discussion about weight (no measurement taken) & $31(2 \cdot 1)$ & $14(1 \cdot 0)$ & $35(2 \cdot 5)$ & $<0.05$ & NS & $<0 \cdot 01$ \\
\hline Diet & $20(1 \cdot 4)$ & $19(1 \cdot 3)$ & $34(2 \cdot 4)$ & NS & NS & NS \\
\hline Discussion about immunisation & $4(0 \cdot 3)$ & $2(0 \cdot 1)$ & $21(1 \cdot 5)$ & NS & $<0.001$ & $<0 \cdot 001$ \\
\hline Exercise & $10(0 \cdot 7)$ & $6(0 \cdot 4)$ & $16(1 \cdot 1)$ & NS & NS & NS \\
\hline Discussion about cervical cytology (smear not taken) & $25(1 \cdot 7)$ & $23(1 \cdot 6)$ & $38(2 \cdot 7)$ & NS & NS & NS \\
\hline One or more of above items & $147(9 \cdot 9)$ & $126(8 \cdot 8)$ & $218(15 \cdot 5)$ & NS & $<0 \cdot 001$ & $<0.001$ \\
\hline
\end{tabular}




\begin{tabular}{|c|c|c|c|c|c|c|}
\hline & \multirow{2}{*}{$\begin{array}{c}\text { First } \\
\text { control session } \\
\text { (A) }\end{array}$} & \multirow{2}{*}{$\begin{array}{l}\text { Second } \\
\text { control session } \\
\text { (B) }\end{array}$} & \multirow{2}{*}{$\begin{array}{l}\text { Experimental } \\
\text { session } \\
\text { (C) }\end{array}$} & \multicolumn{3}{|c|}{ p Value } \\
\hline & & & & (A) $v(\mathrm{~B})$ & (A) $v(\mathrm{C})$ & (B) $v(\mathrm{C})$ \\
\hline Was smoking mentioned? & $12 \cdot 4(125 / 1009)$ & $12 \cdot 1 \quad(95 / 786)$ & $16 \cdot 9(153 / 906)$ & NS & $<0 \cdot 05$ & $<0.05$ \\
\hline Current smoker & $28 \cdot 6(294 / 1028)$ & $25 \cdot 8(212 / 822)$ & $27 \cdot 6(258 / 934)$ & NS & NS & NS \\
\hline Current smokers reporting advice & $20 \cdot 7(61 / 294)$ & $19 \cdot 8(42 / 212)$ & $31.8(82 / 258)$ & NS & $<0.01$ & $<0.01$ \\
\hline \multicolumn{7}{|l|}{ Blood pressure measured (ages 35-65 only): } \\
\hline Today & $25 \cdot 9(110 / 425)$ & $24 \cdot 2(83 / 343)$ & $38 \cdot 5(158 / 410)$ & NS & $<0.001$ & $<0.001$ \\
\hline Today or within past five years & $87 \cdot 7(373 / 425)$ & $90 \cdot 0(309 / 343)$ & $96 \cdot 8(397 / 410)$ & NS & $<0.001$ & $<0.001$ \\
\hline Was alcohol mentioned? & $4 \cdot 5(47 / 1054)$ & $5 \cdot 0(42 / 839)$ & $7 \cdot 0(67 / 956)$ & NS & $<0.05$ & NS \\
\hline Was diet mentioned? & $10 \cdot 6(112 / 1052)$ & $11 \cdot 3(951 / 839)$ & $11 \cdot 4(108 / 950)$ & NS & NS & NS \\
\hline Did doctor talk about general health? & $55 \cdot 8(584 / 1046)$ & $50 \cdot 4(415 / 824)$ & $59 \cdot 1(555 / 939)$ & $<0 \cdot 05$ & NS & $<0.01$ \\
\hline Did doctor talk about previous health problems? & $32 \cdot 7(341 / 1042)$ & $34 \cdot 2(281 / 821)$ & $40 \cdot 8(382 / 937)$ & NS & $<0.001$ & $<0.01$ \\
\hline
\end{tabular}

TABLE IV - Numbers (percentages) of consultations with one or more health education items on audiotape analysis and in medical record

\begin{tabular}{lllll}
\hline & $\begin{array}{c}\text { First } \\
\text { control } \\
\text { session } \\
(\mathbf{n}=229)\end{array}$ & $\begin{array}{c}\text { Second } \\
\text { control } \\
\text { session } \\
(\mathbf{n}=180)\end{array}$ & $\begin{array}{c}\text { Experimental } \\
\text { session } \\
(\mathbf{n}=275)\end{array}$ & $\begin{array}{c}\text { Total } \\
(\mathbf{n}=684)\end{array}$ \\
\hline $\begin{array}{l}\text { One or more health education items on audiotape } \\
\text { One or more health education items in medical records }\end{array}$ & $\begin{array}{c}58(25 \cdot 3) \\
23(10 \cdot 0)\end{array}$ & $\begin{array}{l}44(24 \cdot 4) \\
14(7 \cdot 8)\end{array}$ & $\begin{array}{c}78(28 \cdot 4) \\
30(10 \cdot 9)\end{array}$ & $\begin{array}{c}180(26 \cdot 3) \\
67(9 \cdot 8)\end{array}$ \\
\hline
\end{tabular}

experimental sessions, more patients reporting such activities. The questionnaire was completed after $65 \cdot 8 \%$ of consultations $(72 \cdot 1 \%, 58 \cdot 0 \%$, and $67 \cdot 3 \%$ in first control, second control, and experimental sessions respectively; $\mathrm{p}<0.001, \mathrm{df}=2$ ). Patients were asked whether specific items of health education had been discussed and, for patients aged 35-65, whether their blood pressure had been measured at the index consultation or within the past five years.

Table III gives the results from the questionnaire. Current smokers, who were equally prevalent in all types of surgery, were much more likely to report advice about smoking in the experimental sessions (32\% compared with $20 \%$ and $21 \%$ in control sessions). More blood pressure measurement was reported in the experimental sessions, which increased the proportion of 35-65 year olds reporting such a procedure in the past five years to $97 \%$ (compared with $88 \%$ and $90 \%$ in control sessions). Advice on alcohol consumption was greatest in the 10 minute sessions, though the difference was significant only compared with the first control session. Previous health problems were more likely to be discussed in the longer sessions, but discussion of general health showed no consistent pattern.

The 36 sessions that were audiotaped included 684 consultations for which information from the medical record was available. Mean length of consultation on audiotape was slightly less than that measured by direct observation (mean 7.03 minutes $v 7.36$ minutes), and this difference was consistent between control and experimental sessions. Table IV shows the proportions of consultations including one or more items of health education recorded in the notes and detected on audiotape. On both assessments there was more health promotion activity in the experimental sessions, although differences did not reach significance. For each type of session the number of consultations in which health education was detected on audiotape was more than twice that recorded in the notes $(p<0.01$; McNemar's test). The extent of agreement between the two sources did not differ (Cohen's $x \quad 0 \cdot 41$, $0 \cdot 30$, and 0.34 in first control, second control, and experimental sessions respectively). Similarly, health education items were detected more frequently on the audiotape than in the medical record $(p<0.01$; McNemar's sign test) but the extent of agreement did not differ (Cohen's $x 0.41,0.30$, and 0.34 in first control, second control, and experimental sessions).

Sixty records were used to measure interobserver variation in data extraction. Records were examined by $\mathrm{AW}, \mathrm{PM}$, and $\mathrm{LH}$ or JC, agreement between pairs measured by Cohen's $x$ statistic, and a mean score calculated. Agreement was high $(0.86)$ for extraction of examination findings but only moderate $(0.41)$ for health education items. Twenty five audiotaped consultations were used to measure interobserver agreement. This was found to be high for both heaith education and examination activities $(0.74,0.84)$. Interpretations of Cohen's $\varkappa$ statistic were taken from Landis and Koch. ${ }^{17}$

\section{Discussion}

This study found an increase in recording of health promotion activities by general practitioners in the sessions booked at longer intervals and a higher level of reporting of such activities by patients. Comparison of problem classification showed no differences between the experimental and second control sessions and only a slightly different mix in the first control session, which was probably due to seasonal factors. Further support for the mix of patients in the experimental and control sessions being comparable was the nearly identical prescribing rates in all three types of session. It was not possible for the research assistants to be unaware of whether they were monitoring an experimental or control session, as their tasks included administering the project at the practice. The consistency of data on examinations and health education between the patient questionnaire and the medical records suggests that bias in extraction from the medical record did not occur.

The level of agreement between raters in extraction from the medical record was only moderate for health education. These errors in classification may have led us to underestimate the difference in recording of health promotion between control sessions and sessions booked at 10 minute intervals. As far as possible the same research assistant was concerned with each doctor and so the effect of interobserver variability was reduced.

Although response rates to the questionnaire differed between types of surgery, this would be a source of bias only if completion of the questionnaire was associated with one of the factors that it sought to measure. The likeliest reason for the differences was that several patients in the experimental and second control sessions had already completed the questionnaire once and were reluctant to do so again.

The number of patients booked per session might have affected our results as this was slightly less (by an average of three patients) in the experimental sessions. It is highly unlikely that this change alone would alter the behaviour of doctors in the consultation, and no empirical studies support this suggestion. We therefore conclude that the association between appointment length and health promotion in the consultation is real and causal. Perhaps the most surprising finding was that such a small increase in contact between 
patient and doctor led to considerable increases in health promotion, suggesting that this activity was previously compromised by lack of time. Our findings also confirm that other aspects of doctors' behaviour, notably prescribing, are not sensitive to changes in availability of time.

The most striking change in health promotion activity was screening for hypertension. That nearly all patients aged 35-65 who consulted in the experimental sessions reported a blood pressure check in the past five years suggests that for this procedure opportunistic screening can be made to work if sufficient time is available. A similar increase was reported by Morrell et $a l^{10}$ but not confirmed by Ridsdale et al ${ }^{12}$ As Ridsdale et al carried out their study in a practice already operating a 10 minute appointment system it is plausible that the need for case finding had already been met.

In the sessions booked at 10 minute intervals patients reported that smoking and alcohol consumption were mentioned in $17 \%$ and $7 \%$ of consultations respectively. These are close to the estimated percentages of consultations in which these variables contribute to the presenting complaint, ${ }^{7}$ and suggest that the extra time available is being used to broaden the consultation in this way. Records were not examined for previous recording of lifestyle factors and so it is not possible to estimate how far these topics were raised as a screening procedure.

Morrell et al found that more vaginal examinations were performed in sessions booked at 10 minute intervals and suggested that this was because of more cervical smears being taken. ${ }^{10}$ We found no such association, possibly because in many practices the cervical cytology programme was conducted separately from routine consultations. It was disappointing, however, that discussion of this topic did not increase, as such opportunistic reminders have been shown to be effective. ${ }^{18}$

An incidental finding was that over twice as many consultations included a health education topic on audiotape analysis compared with the medical record. This questions the validity of audit relying on medical record analysis. ${ }^{19}$ Patient satisfaction questionnaires are increasingly seen as an appropriate method of audit. ${ }^{20}$ We have shown these also to have a place in assessing the content of consultations.

This and other studies have examined short term effects of changes in appointment length. It is possible that long term effects of such a change might include a reduction in consultation rates by patients. Studies to examine this issue could also assess whether changes in doctor behaviour are due to novelty effect or if they are sustainable in the long term.

In summary, our findings show that an extension of appointment length and a more modest increase in consultation length have an important impact on health promotion activities in the consultation. Priorities are seen to be smoking and screening for hypertension. Negative results shown for other topics, such as exercise, emphasise the need for additional methods of health promotion activity in primary care. Most doctors continue to book patients at a rate of eight or more an hour, and most think that longer appointments would be beneficial. Those who are able to do so should therefore be encouraged to change to 10 minute appointments. Health service policy should enable more doctors to respond in this way. In areas with high annual consultation rates this can only be achieved by a reduction in list size. ${ }^{21}$ It is a paradox of the new contract $^{3}$ that, despite its emphasis on health promotion, it may result in doctors feeling that their increased workload does not permit longer consultations.
We are grateful for the support of participating general practitioners, their staff, and their patients. The study was funded by the Health Promotion Research Trust.

\section{Appendix}

GUIDELINES FOR EXTRACTING DATA FROM MEDICAL RECORD

Examinations-Only record that an examination has been performed if there is clear evidence of this in the medical record. If a phrase may or may not be a record of an examination do not include. For example, "red eye, 2 days" does not necessarily imply that the doctor has made an ophthalmological examination. "Tenderness" should be interpreted as an examination finding. The following examinations will be classified as health promotion activities: blood pressure; weight; taking a cervical smear.

Health education - When any mention is made of diet, smoking, alcohol, or exercise record as health education. Recording of numbers of cigarettes smoked, amount of alcohol consumed, etc, would be included. Comments such as "increase fibre intake," "swims," or "advised to swim" would also be considered health education. An exercise related event (for example, twisted knee playing football) does not constitute health education. Examination of breasts, weight, or blood pressure should not be coded as health education, but entry of a discussion of these topics should be so classified. Discussion of immunisation should be recorded as health education; actual immunisation should not. Cervical cytology should not be included when a smear has been taken or results recorded. Cervical cytology should be noted, however, if smears have been otherwise discussed-for example, smear due, smear to be booked, or smear recently taken, etc. Up to four of the following may be recorded per consultation: diet; smoking; alcohol; exercise; immunisation; tuition of breast self examination; discussion about cervical cytology; discussion about weight.

1 World Health Organisation. Primary health care. Presented at the international conference on primary health care, Alma Ata, USSR, September 6-12, 1978. Geneva: WHO, 1978

2 Royal College of General Practitioners. Health and prevention in primary care. London: RCGP, 1981. (Reports from general practice, No 18. )

3 Department of Health and Welsh Office. General practice in the National Health Service. A new contract. London: $\mathrm{DoH}, 1989$.

4 Stott $\mathrm{NCH}$, Davis $\mathrm{RH}$. The exceptional potential of every primary care consultation. 7 R Coll Gen Pract 1979;29:201-5.

5 Tones BK. Health promotion - a new panacea. Journal of the Institute of Health Education 1985;23:16-21.

6 Stott NCH. Primary health care. Bridging the gap between theory and practice. Berlin: Springer-Verlag, 1983.

7 Boulton MG, Williams A. Health education in general practice consultations: doctors' advice on alcohol, diet and smoking. Health Education fournal 1983;42:57-63.

8 Wallace PG, Brennan PJ, Haines AP. Are general practitioners doing enough to promote healthy lifestyle? Findings of the Medical Research Council's general practice research framework study on lifestyle and health. $B M \mathcal{J}$ 1987;294:940-2

9 Fleming DM, Lawrence MSTA, Cross KW. List size, screening methods, and other characteristics of practices in relation to preventive care. $B M F$ 1985;291:869-72.

10 Morrell DC, Evans ME, Morris RW, Roland MO. The "five minute" consultation: Effect of time constraint on clinical content and patient satisfaction. BMF 1986;292:870-3

11 Roland MO, Bartholomew J, Courtenay MJF, Morris RW, Morrell DC. The "five minute" consultation: effect of time constraint on verbal communication. BMF 1986;292:874-6.

12 Ridsdale L, Carruthers M, Morris R, Ridsdale J. Study of the effect of time availability on the consultation. $f R$ Coll Gen Pract 1989;39:488-91.

13 Wilson A. Extending appointment length - the effect in one practice. $f R$ Coll Gen Pract 1989;39:24-5.

14 Wilson $\mathrm{A}$. Consultation length: general practitioners' attitudes and practices. BMf $1985 ; 290: 1322-4$.

15 Wilson A, McDonald P, Hayes L, Cooney J. Longer booking intervals in general practice: effects on doctors' stress and arousal. $\mathrm{Br}$ J Gen Pract 1991; $41: 184-7$.

16 Siegel S, Castellan NJ. Non-parametric statistics for the behavioral sciences. 2nd ed. New York: McGraw-Hill, 1988.

17 Landis JR, Koch SG. The measurement of observer agreement for categorical data. Biometrics 1977;33:159-74.

18 Pierce M, Lundy S, Palanisamy A, Winning S, King J. Prospective randomised controlled trial of call and recall for cervical cytology screening. BMF 1989;299:160-2.

19 Mant D, McKinlay C, Fuller A, Randall T, Fulford EM, Muir J. Three year follow up of patients with raised blood pressure identified at health checks in follow up of patients with raised blood press

20 Fitzpatrick $R$. Surveys of patient satisfaction: 1 : important general considerations. BMF 1991;302:887-9.

21 Morrell $D$, Roland $M$. How can good general practitioner care be achieved? BMF 1987;294:161-2.

(Accepted 30 October 1991) 